\title{
Development of multifunctional materials and structures with improved capacities in aerodynamics, de-icing, acoustics or electromagnetism for civil and military aircraft \\ EMUS 2019
}

\author{
BENOIT BERTON \\ Dassault Aviation \\ 78 quai M. Dassault \\ 92552 St Cloud Cedex, France \\ e-mail: benoit.berton@dassault-aviation.com
}

Key words: multifunctional structures, smart materials, acoustics, icing protection, antennas

\begin{abstract}
.
For several years, either in the frame of research projects (French, European), or for direct application on aircraft programs, Dassault Aviation has developed multifunctional materials and structures (MMS) with specific benefits in aerodynamics, de-icing, acoustic or electromagnetisms. The main challenge is to get the best compromise between the high functional performances desired and the mechanical and aeronautic environment resistance needed for the application. This presentation will review some examples of development performed in the recent years for aircraft aerodynamics improvement, icing protection, acoustics and new antenna radomes.
\end{abstract}

\section{INTRODUCTION}

The design of advanced multifunctional materials and structures is really a challenge for the aerospace industry. Indeed, aeronautic structures that combine mechanical and aeronautic environment resistance with a specific functional property like acoustic, aerodynamic, electromagnetism.... are gathering more and more attention. Such materials and structures can only be passive but can also present some active characteristics, including sensors, actuators and processors, leading to the smart materials and structures (SMS) concept. Innovation also comes from new manufacturing and modelling techniques, especially in the composites domain which provide opportunities for integration of dedicated functional components. In the following sections, examples of such development carried out at Dassault Aviation will be given. 


\section{GENERAL SPECIFICATIONS FOR AERONAUTIC APPLICATIONS}

As reminded in the introduction, multifunctional materials and structures can be defined as materials that exhibit a specific functionality in addition to resistance to aeronautic environment. Consequently, it is important to describe the multiple constraints that must be fulfilled in order to be implemented in an aircraft like the Falcon 7X (Figure 1).

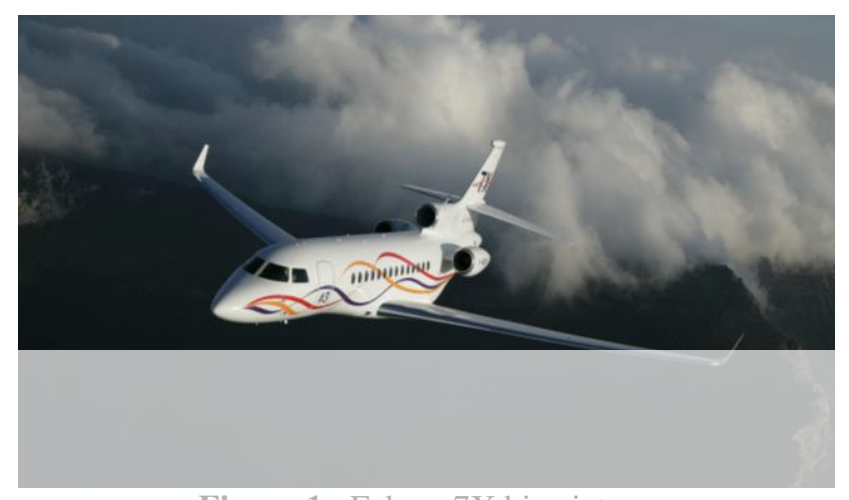

Figure 1 : Falcon $7 \mathrm{X}$ bizz jet

\section{Such general constraints are the following :}
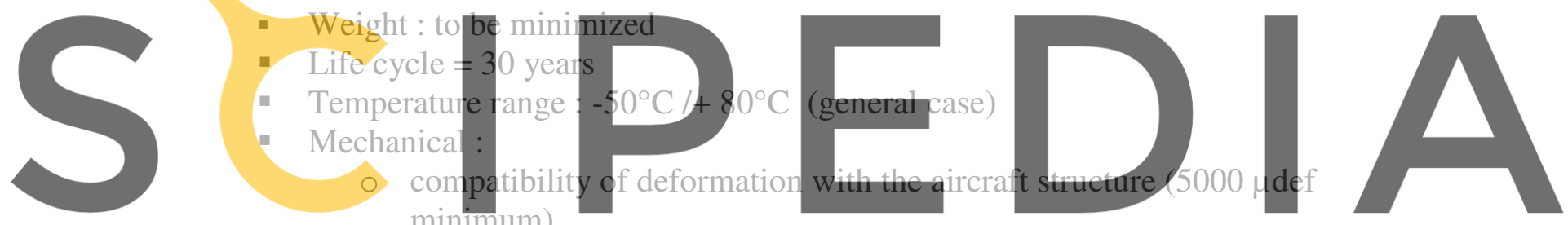

fatigue life : $10^{6}$ cycles@ $1000 \mu$ def

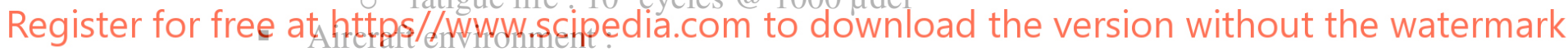

wet aging $\left(70^{\circ} \mathrm{C}, 85 \% \mathrm{RH}\right)$, salt spray ...

O resistance to aeronautic fluids : cleaning fluids, fuel, hydraulic fluids, grease, de-icing fluids,...

$\circ$ erosion resistance (rain, sands)

- Electromagnetic compatibility, lightning, high intensity fields

- Manufacturing aspects

○ Withstand the bonding cycle on metal or co-curing cycle in composites @ $180^{\circ} \mathrm{C}$ 


\section{MULTIFUNCTIONAL STRUCTURES}

Examples of multifunctional structures developed at Dassault Aviation for some years are presented below:

\subsection{Aerodynamics functionalities}

Aerodynamic optimization of the airfoil design is of course a key point of every new aircraft programs. Especially, for Falcon business jets that are devoted to long range operations, improvement of aerodynamic characteristics such as the drag in cruise is a regular effort of engineers. In the following sections, two examples of application of MMS are presented.

3.1.1 Trailing edge shape control with smart materials

For civil aircraft and long endurance UAV, aerodynamic optimisation of the wings is important in order to enhance the endurance. Especially, the capability to reduce the wave drag in transonic cruise at flight altitude without increasing the drag at lower $\mathrm{Cl}$ or lower Mach number can be very promising. This can be achieved by modifying the shape of the trailing edge from a divergent one at flight altitude to a straight one in the transition regimes.
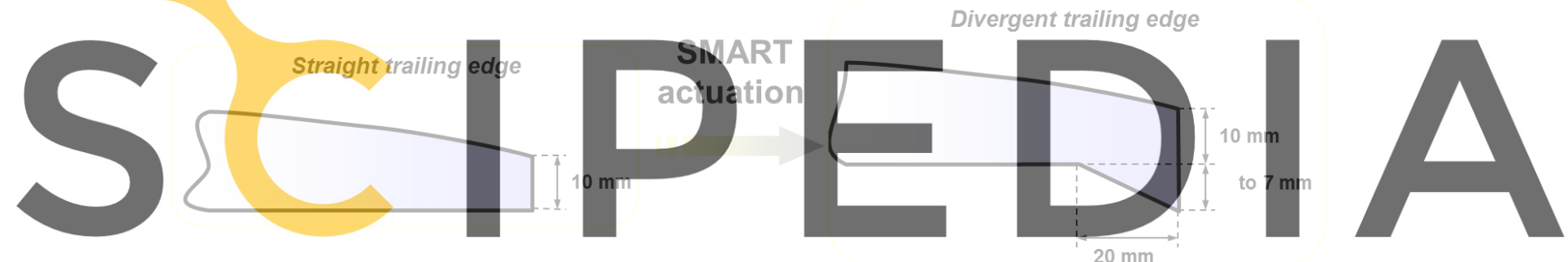
Register for free at https//www.scipedia.com to download the version without.the watermark memory alloys (SMA) as actuators. Ni-Ti wires with two-way effect respond to a heat stimulus resulting in a crystalline transition and a length modification. Such development has been launched at Dassault in the frame of an European EUCLID research program: CASS.

A demonstrator has been manufactured based on the generic geometry of a wing aileron. External dimensions are $300 \mathrm{~mm}$ along the chord and $500 \mathrm{~mm}$ along the span. This aileron is split in 2 parts as shown on figure 2 :

- a forward box with the main function is to withstand the structural loads (200 $\mathrm{mm}$ along the chord).

- a rearward box with the adaptive part and the actuation system (100 mm along the chord). However, for spacing reasons, the SMA wires are located in the forward box (fig 2). The actuation system has been designed to fulfil the aerodynamic specification 


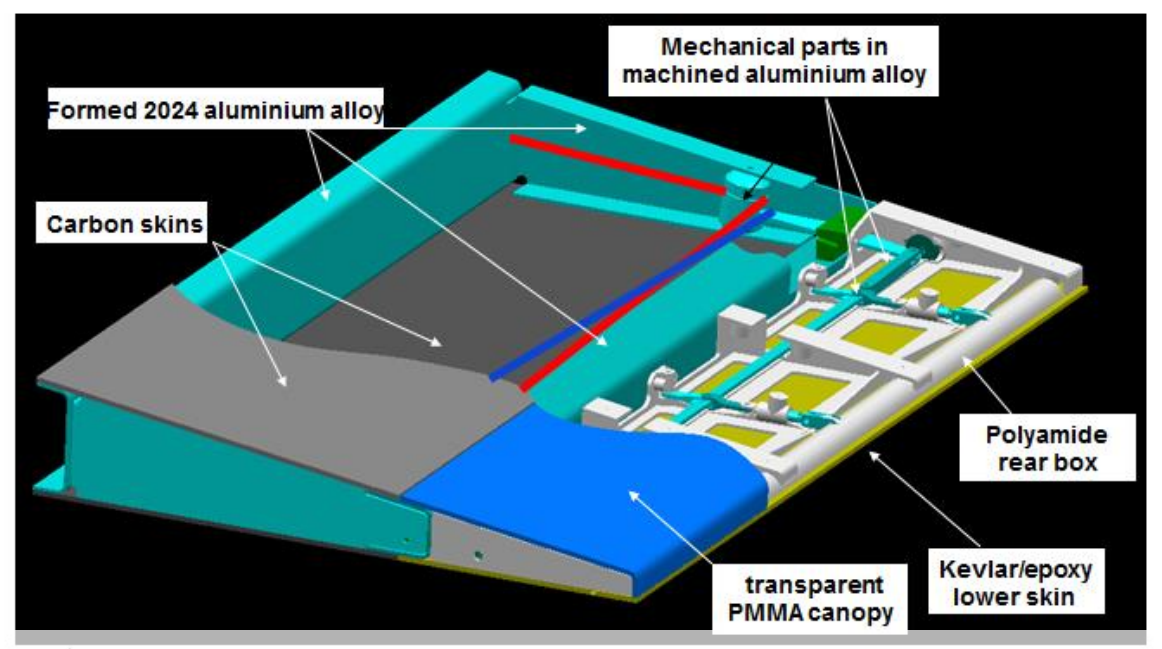

Figure 2 : divergent trailing edge demonstrator design

This demonstrator has been tested in Dassault lab regarding its functional performance at virgin state and under environment (figure 3). Especially, the SMA actuators reliability has been verified at low and high temperature and under repetitive temperature cycling.

Specifications have been demonstrated in terms of deflection and response time.
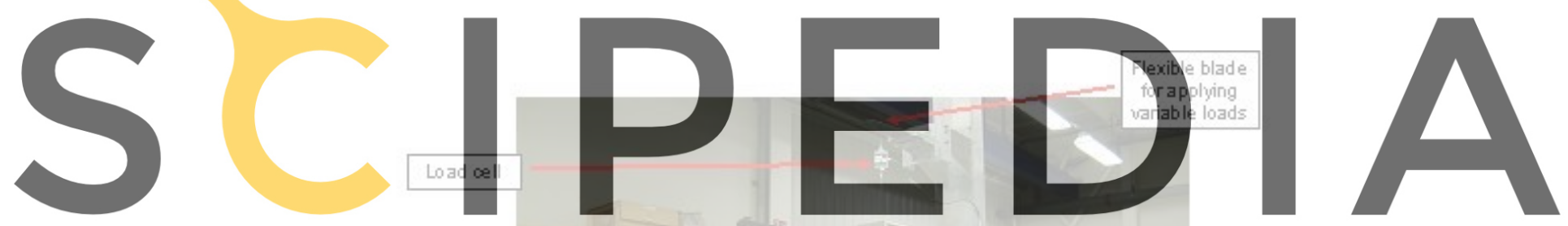

Register for free at https//www.scipedia.com to download the version without the watermark

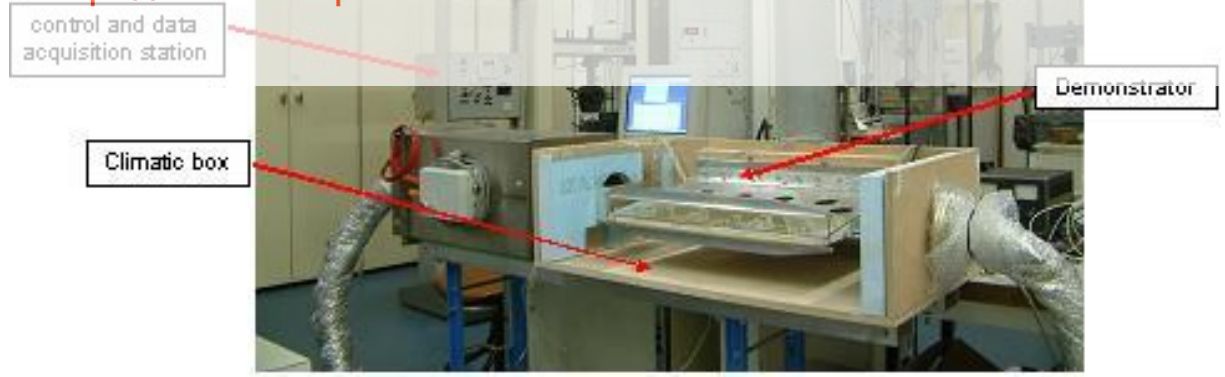

Figure 3 : functional ground test of the smart demonstrator

\subsubsection{Multifunctional materials for laminar surfaces}

Laminar flow technologies that exploit the low drag characteristics of laminar boundary layers on aircraft surfaces, such as wings, engine nacelles and empennage, have the potential to produce a significant reduction in drag. However, the application of these laminar flow 
technologies in a commercial environment is still hindered by unanswered questions regarding its operational reliability. Contamination of leading edges by insects is a concern as excrescences can cause transition of the boundary layer, as ice accretion, reducing the potential drag benefit. Another cause of premature transition is surface roughness; poor durability of leading edge coatings and materials is thus another concern. Prolonged exposure to high velocity water impact (flight through rain) can cause erosion of anti-contamination surfaces, leading to a temporary or complete loss of laminar flow. These topics have been studied through a combination of flight and laboratory test campaigns, in part, within the European Commission funded AEROMUCO project.

In particular, several multifunctional coatings have been developed by members of the consortium with different approaches. These new materials have been characterized regarding laminar functionalities (contamination, erosion, icing) and aeronautic specifications.

Then, Dassault was in charge of a flight test campaign conducted in 2013 at the Istres Dassault Flight Center to evaluate the most interesting materials. Candidate surface preparations were applied to strips of tape. Two types of tape were used: aluminium foil (3M) and PET-Polyethylene Terephthalate tape. The tape was adhered to the leading edge of the horizontal tail plane of a Falcon 7X (Figure 4).
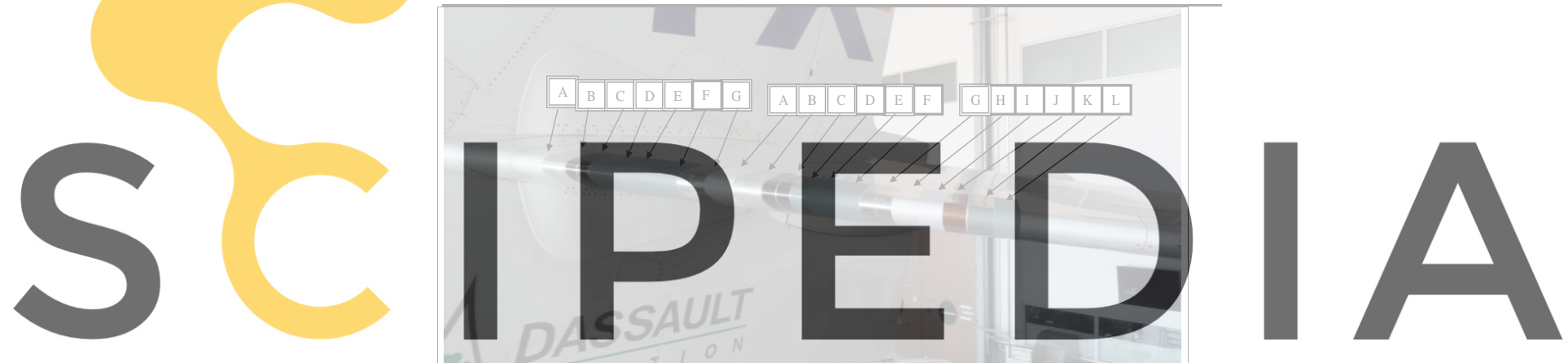

Register for free at https//www.scipedia.com to download the version without the watermark

Figure 4 : laminar coatings installed on the horizontal tail plane of a Faicon $7 \mathrm{X}$

Materials samples have been let on the aircraft during several months. Therefore, their durability in real flight environment could be evaluated. Moreover, their efficiency towards leading edge contamination could be assessed. In the tested conditions, most of materials avoid the presence of contamination above the transition criteria.

\subsection{Icing protection functionalities}

Icing of aircraft aerodynamic surfaces and engines is a complex and demanding challenge, and several research activities have already addressed the issue of ice accretion because of the threat to aviation safety. These difficulties are increased by the recent changes in certification regulations, which will require manufacturers to certify their products against more stringent requirements.

Dassault Aviation is fully involved in this problematic to optimize the icing protection of Falcon business jets (figure 5). 

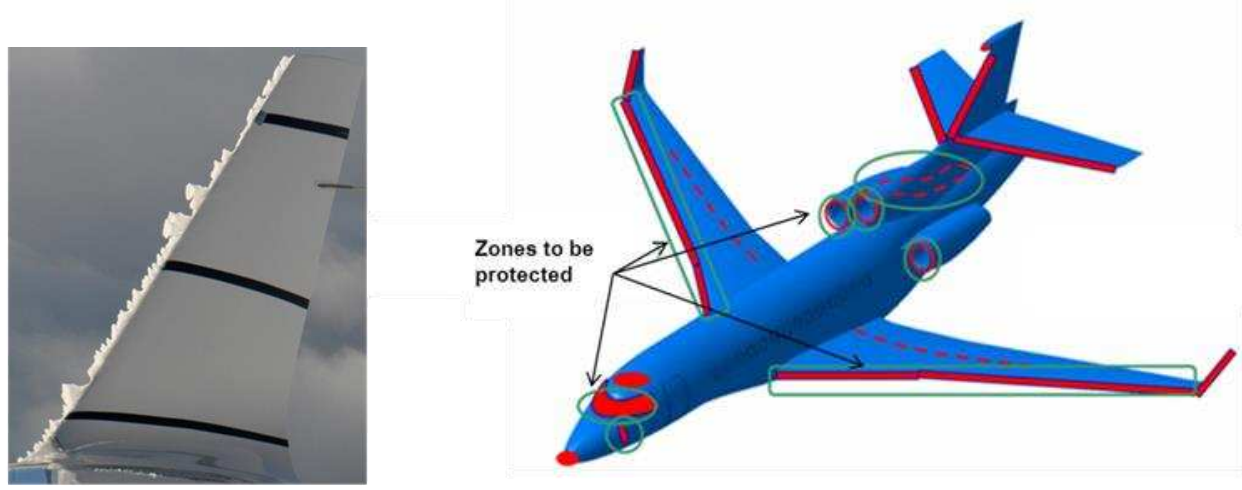

Figure 5 : ice accretion zones (in red) of a Falcon jet and protected areas.

Indeed, Dassault participates to research projects with industries and research organizations to develop new technologies for wing ice protection systems (WIPS), as Clean sky, HAIC, Jedi Ace EU projects...Even if the existing technologies, like bleed air, have worked well for decades in aircraft systems, the potential to further improve aircraft safety and reduce energy consumption with these new technologies is rather high. In particular, anti-icing coatings

("icephobics") combined with electro-thermal system appears to be extremely promising.
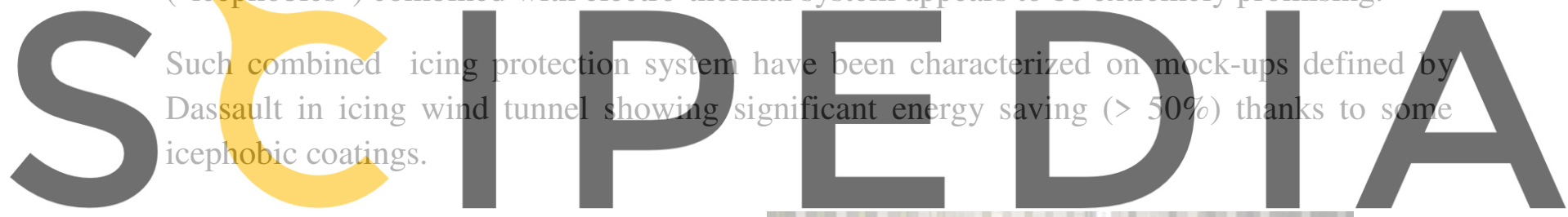

Register for free at https//www.scipedia.com

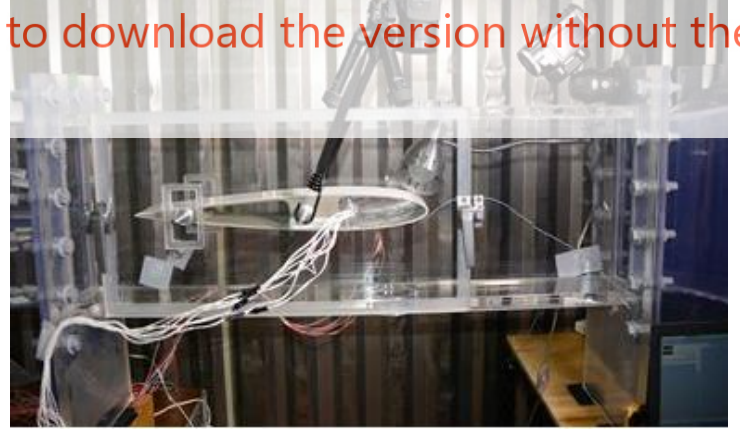

Figure 6 : airfoil mock-up equipped with electrothermal mats and icephobic coatings in icing wind tunnel.

\subsection{Acoustic functionalities}

Acoustic comfort of business jets is also an important design criterion for structure engineers as the noise level inside the cabin during flight is clearly a criteria of choice to buy a new aircraft. In that sense, Falcon $7 \mathrm{X}$ and $8 \mathrm{X}$ appear to be amongst the most silent aircrafts on the market.

Consequently, a large effort is put at Dassault to optimize the acoustic protection of the 
cabin. Based on vibro-acoustic simulations of the aircraft, absorbing and damping materials are added on dedicated zones of the fuselage and trim panels with a constant effort to minimize the weight. In that sense, it can be worthwhile to integrate the damping component within the composite structures to optimize the weight added. Such approach has been followed some years ago in the frame of carbon composite fuselage development (FUBACOMP and FACE projects- figure 7).

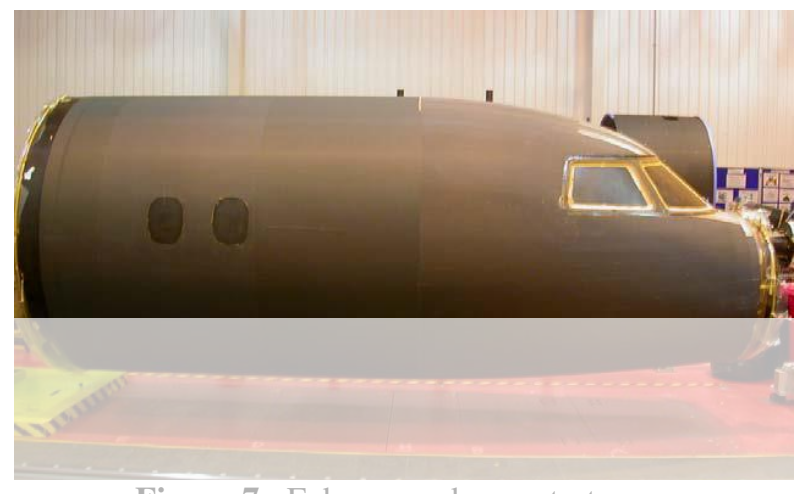

Figure 7 : Fubacomp demonstrator

In cooperation with a material manufacturer, Dassault has developed a damped composite material with integration of a viscoelastic layer between two carbon composite skins (figure 8). Definition of the naterials of the skins and of the corresponding thicknesses has been done to get the best compromise between the vibro-acoustic resistance (shear). Another challenge comes combine right curing of layer. arbon composite sk kin with the

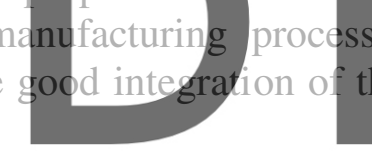
that shall

Register for frearatihttps//www.scipedia.com to download the version without the watermark composite skin

\section{laver}

Figure 8 : damped composite architecture

The new composite material has been characterized in damping properties (Oberst test figure 9) with damping up to $50 \%$ in the $1000-2000 \mathrm{~Hz}$ range. 


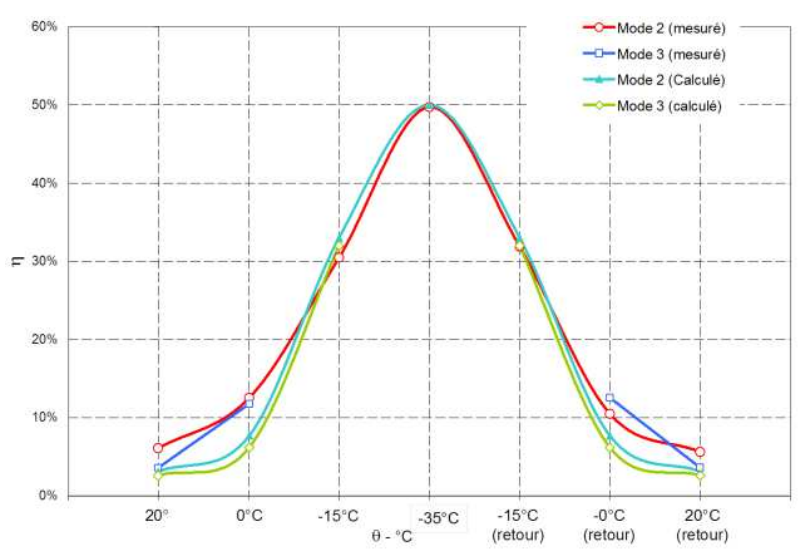

Figure 9 : damping properties of the composite

Similarly, mechanical tests were conducted on the damped composite material as the 4 points bending test, shown on figure 10, and buckling test. Finite element models have been developed to simulate the behavior of this new composite.
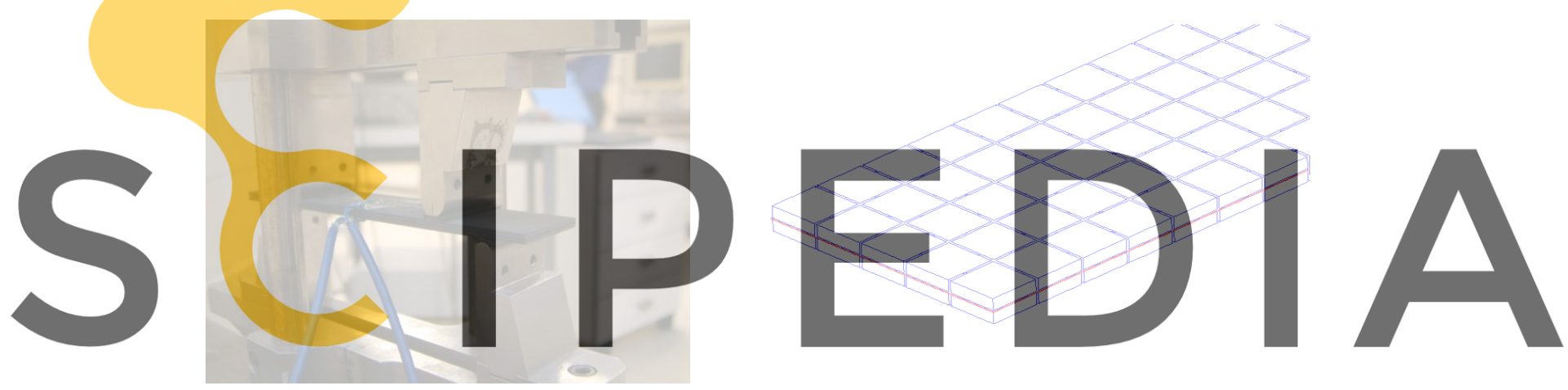

Register for free at https/fwyww scipedia.com to download the version without the watermark

\subsection{Electromagnetic functionalities}

Electromagnetic functionality is also an important application case of MMS as illustrated on the two examples below.

\subsubsection{Antennas application}

Recent aircraft integrate more and more antenna systems that cover different functions and work in different frequency ranges.

To deal with the multiplication of antenna embarked in future aircraft, Dassault aviation evaluate the interest of conformal and integrated antennas in composite structures. At this time, we are still at a development stage for civil application.

Regarding new antenna systems which operate in novel frequencies ranges, that induce the needs of specific radomes. Such problematic has been recently encountered for a new Satcom 
communication system for Falcon jets, where Dassault has launched the development of a new radome part. As presented in figure 11, different architectures of radomes can be considered with different bandwidth and attenuation performances. These architectures consist in superposition of alternate layers of "high" permittivity and low permittivity materials.

\begin{tabular}{|l|l|l|l|}
\hline Monolithique & Sandwich A & Sandwich B & Sandwich C \\
\hline$\lambda / 2$ & & & \\
\hline
\end{tabular}

Figure 11 : different types of antenna radome architectures

Therefore, for this new radome development, Dassault has prospected and evaluated a lot of low permittivity and low loss materials. Such materials have been characterized on a free space test rig (figure 12) in Dassault lab. This test campaign has allowed to select the best candidate materials and to design the sandwich structure suitable for the antenna system and compatible with the functional and operational requirements.
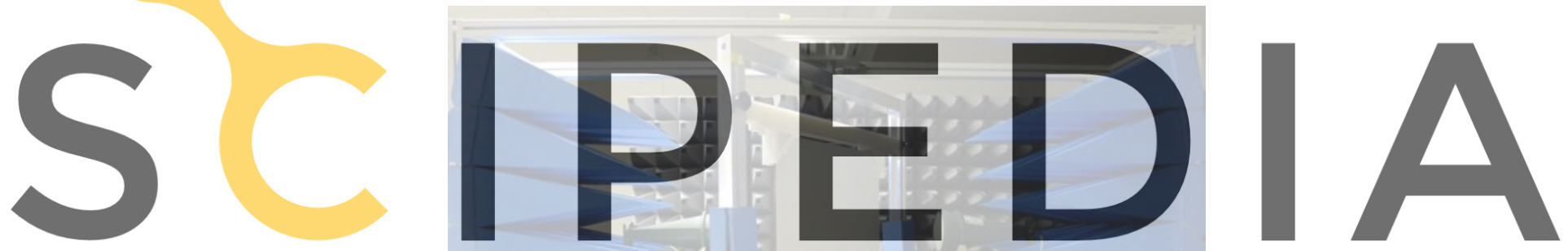

Register for free at https//www.scipedia.com to download the version without the watermark

Figure 12 : EM transparency test in Dassault lab

\subsubsection{Low observability MMS}

Although the previous illustrations were principally oriented to civil application, Dassault Aviation is of course also largely involved in military aircraft. Consequently, for decades, the company has developed Low Observability concepts, acting on the aircraft shapes but also on different absorbing materials as well. This approach has mainly been applied on the Rafale fighter and to a larger extent on the Neuron UCAV demonstrator that first flew in 2012 (figure 13 below).

If details of such low observability materials and structures cannot be revealed, the development principles are similar to the examples presented above, resulting in multi-layers 
composite structures.

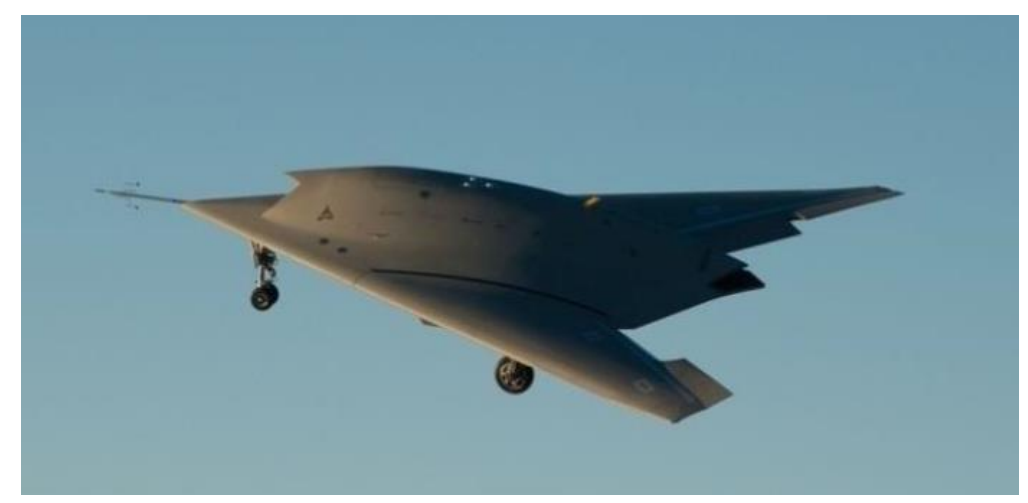

Figure 13 : Neuron low observability demonstrator

\section{CONCLUSIONS}

Different types of multifunctional materials and structures have been developed at Dassault Aviation during the recent years. Maturity of these solutions ranges from medium TRL development to serial production. If the applications appear to be very diverse, the development principles are in general similar. in all these developments:

- a strong implication to optimize the multifu

- the use of composite manufacturing
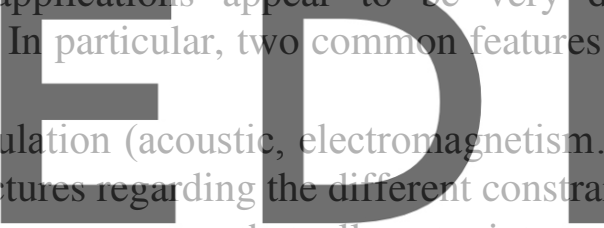

(a)

rocesses th

that allow to integrate different

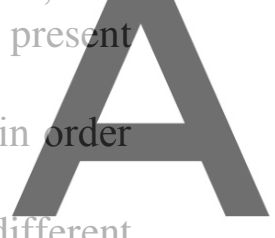

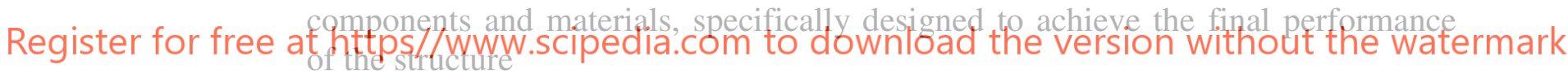

\section{REFERENCES}

[1] Berton B. - Shape Memory Applications Trailing edge shape control - RTO conference AVT - 141 Multifunctional Structures - 2006

[2] Berton B. \& al - Evaluation of functional coatings for laminar flow applications on future business jets through ground and flight testing- conference AIAA - ATO 2014

[3] Rehfeld N. \& al - JediAce: Japanese-European De-icing Aircraft Collaborative Exploration - Conference Aerodays - London - 2016 